\title{
Predicting Fatigue in Patients Using Home Parenteral Nutrition: A Longitudinal Study
}

\author{
Getty Huisman-de Waal • Ellen Bazelmans • \\ Theo van Achterberg • Jan Jansen • Hans Sauerwein • \\ Geert Wanten $\cdot$ Lisette Schoonhoven
}

Published online: 24 September 2010

(C) The Author(s) 2010. This article is published with open access at Springerlink.com

\begin{abstract}
Background Home parenteral nutrition (HPN) is a lifesaving therapy for patients with diseases that preclude adequate oral or enteral food intake. HPN has a large impact on daily life. Many patients suffer from fatigue and depression, and they experience limits in social activities. This all contributes to a lower quality of life.

Purpose Fatigue is the most frequently mentioned problem in Dutch HPN patients. Therefore, we studied the prevalence, course and predictors of fatigue in these patients.
\end{abstract}

G. Huisman-de Waal • T. van Achterberg • L. Schoonhoven

IQ healthcare, Nursing Science,

Radboud University Nijmegen Medical Centre,

Nijmegen, the Netherlands

\section{E. Bazelmans}

Department of Medical Psychology,

Radboud University Nijmegen Medical Centre,

Nijmegen, the Netherlands

G. Huisman-de Waal $\cdot$ G. Wanten

Department of Gastroenterology and Hepatology,

Radboud University Nijmegen Medical Centre,

Nijmegen, the Netherlands

\section{H. Sauerwein}

Department of Endocrinology and Metabolism,

University Medical Centre Amsterdam,

Amsterdam, the Netherlands

\section{G. Huisman-de Waal $(\triangle)$}

Radboud University Nijmegen Medical Centre 114-Scientific Institute for Quality of Healthcare,

PO Box 9101, 6500 HB Nijmegen, the Netherlands

e-mail: G.Huisman-deWaal@iq.umcn.nl

\section{J. Jansen}

Department of Internal Medicine Helmond,

Elkerliek Hospital,

Nijmegen, the Netherlands
Methods Patients completed questionnaires at baseline and follow-up (12 months later). Measurements included fatigue, depression, functional impairment, social support, self-efficacy, coping, anxiety and acceptance. Laboratory measures, including total bilirubin, creatinine, albumin and haemoglobin levels, were obtained from the medical records. Descriptive statistics, correlations and linear regression analysis were performed.

Results The response rate was $71 \%(n=75)$. Sixty-five per cent of the patients were severely fatigued $(n=49)$. Eightynine per cent experienced persistent fatigue. Baseline fatigue predicted $57 \%$ of the variance of fatigue at followup, and avoidance was responsible for $3 \%$ of the variance. No significant correlations between fatigue and laboratory measures were found. A cross-sectional analysis showed that $46 \%$ of the variance of fatigue was explained by functional impairment, self-efficacy and depression.

Conclusion Severe fatigue is a persistent problem for HPN patients. Baseline fatigue was the strongest predictor of fatigue at follow-up. Functional impairment, self-efficacy and depression are strongly related to fatigue. Early recognition and treatment of fatigue are important.

Keywords Home parenteral nutrition · Fatigue $\cdot$ Functional impairment. Self-efficacy · Depression

\section{Introduction}

Home parenteral nutrition (HPN) has been used for the management of intestinal failure since the late $60 \mathrm{~s}$ of the previous century. This treatment modality is life-saving for patients with an inadequate oral or enteral food intake of nutrients and fluids. Most patients suffer from intestinal failure due to short bowel syndrome or motility disorders 
[1]. HPN is used alone or in conjunction with oral feeds. The support of patients on HPN requires a dedicated multidisciplinary team. This team should be available for instructions to patients, advice and treatment of complications on a 24/7 basis. During their training period, patients who are fit to perform HPN administration become knowledgeable and skilled in the performance of aseptic techniques, catheter care and the intravenous administration of nutrients. Also, these patients are trained to contact their treatment centre in case of suspected catheter infection, occlusion or other problems of the therapy [2].

Several studies describe that HPN is associated with medical complications [3, 4]. These complications may be related to the central venous catheter or to the nutrition formula [5]. However, HPN also has a major impact on daily life, and many patients suffer from fatigue and depression [6-10]. Not unexpectedly, HPN also limits social activities and impairs quality of life $[8,9]$.

A Dutch study showed that fatigue is the foremost and most frequently mentioned problem in HPN patients. Sixty per cent of the HPN patients were severely fatigued, and fatigue was reported by $90 \%$ of these patients as a main problem in daily life $(n=43)$ [9]. It was found that HPN patients were more fatigued when compared with patients suffering from functional bowel disorder or cerebrovascular accident, and fatigue scores corresponded with those seen in patients with multiple sclerosis. More specifically, a higher level of fatigue was related to the presence of passive coping strategies and believing that good health is determined by fate. Depressive symptoms were present in $65 \%$ of 48 HPN patients, $17 \%$ of whom experienced severe depressive symptoms [9]. Social impairment also was a commonly reported problem. Almost half of the respondents mentioned social limitations as a problem in daily life. Increased social impairment was strongly related to a lower quality of life. Social impairment was more often reported when compared to patients on haemodialysis, cancer patients and patients suffering from rheumatoid arthritis [11].

Fatigue is a common symptom in various chronic diseases. It has mostly been studied in patients with chronic fatigue syndrome, cancer, multiple sclerosis, Parkinson's disease, renal disease and after stroke [12-17]. Physical as well as psychosocial predictors have been reported in the literature. Vercoulen et al. [16] found that $85 \%$ of multiple sclerosis patients and $100 \%$ of chronic fatigue syndrome (CFS) patients felt fatigued at least once a week as compared to only $13 \%$ of the healthy individuals. Several studies show that persistent fatigue is predicted by the presence of fatigue at the baseline measurement [18-20]. Vercoulen et al. [16, 21] developed a multidimensional assessment method for CFS and other chronic disorders. Nine relatively independent dimensions of CFS were identified, namely psychological well-being, functional impairment in daily life, sleep disturbance, concentration problems, physical activity, social functioning, social support, causal attributions and self-efficacy.

In CFS patients, fatigue severity was related to impairment in daily life and low sense of control. Other predictors of fatigue in chronic diseases are depression and anxiety $[15,22,23]$, psychological well-being, high impairment in role functioning, disability, acceptance, self-efficacy and problematic social support [23-25].

Besides psychosocial factors, physiological factors may be related to fatigue. For example, McCann and Boore [12] found that malnutrition causes fatigue in renal failure patients. Srivastava [26] and Piper et al. [27] found that anaemia affects the reported levels of fatigue. Other studies, however, did not find these associations [12, 28-31].

So far, longitudinal studies regarding fatigue in patients on long-term HPN are lacking. The current study presents the longitudinal data of a cohort of HPN patients during a 12month period. Based on the literature in other chronic patient groups, fatigue in HPN patients might be predicted by the presence or absence of disease activity, depression, selfefficacy, coping, acceptance, anxiety, functional impairment and social support. The aims of this study were (1) to describe the prevalence and course of fatigue and (2) to evaluate baseline fatigue and the aforementioned set of psychosocial and physiological factors in the prediction of fatigue.

\section{Method}

\section{Patients}

All 106 HPN patients treated at the Radboud University Nijmegen Medical Centre or the Academic Medical Centre in Amsterdam at the start of the study in October 2007 were asked to participate in this study. These patients represent about $90 \%$ of all patients receiving long-term HPN in the Netherlands. Patients had to be on HPN for at least 3 months at T1. We excluded patients younger than 18 years. The regional committee on Research Involving Human Subjects waived the need for a review of the study because we used questionnaires and medical records only. Patients received a written invitation to participate.

\section{Procedure}

After obtaining a written informed consent, questionnaires were sent to the patients (baseline). Participants were asked to complete the questionnaires within 2 weeks and to return them in a prepaid envelop. After 1 year, a part of the questionnaire was sent again by mail (follow-up), measuring general and HPN-related characteristics, and fatigue. In case of missing 
data, patients were contacted by telephone to complete the questionnaires. Patients who had discontinued HPN at followup were still asked to fill out a questionnaire. Results for these patients were analysed separately. Laboratory measures (taken during regular checkups at the outpatient clinic) were obtained from the medical records at $\mathrm{T} 1$ and $\mathrm{T} 2$.

\section{Measurements}

The questionnaire addressed general and HPN-related characteristics.

\section{Fatigue}

The subscale 'Fatigue Severity' from the Checklist Individual Strength (CIS) is an eight-item questionnaire and measures fatigue during the previous 2 weeks [32]. Each item was scored on a seven-point Likert scale. High scores indicate a high level of experienced fatigue. Severe fatigue was defined as a CIS fatigue score equal to or higher than 35 [21]. A score between 27 and 34 indicates high experience of fatigue. In this study, a score of 35 or above at baseline as well as at follow-up was seen as indicating 'persistent severe fatigue'. The CIS has been tested thoroughly among patients with different chronic diseases and healthy controls $[16,21,32]$. The internal consistency of the CIS is good: Cronbach's $\alpha$ for the total CIS was 0.90 and was 0.88 for the subscale 'fatigue severity'. Convergent validity was previously reported to be satisfactory [33].

\section{Depression}

The Beck Depression Inventory for Primary Care (BDI-PC) was used to assess depression. The BDI-PC does not contain questions concerning physical aspects of fatigue or somatic symptoms of depression [34, 35]. The BDI-PC has seven items and consists of cognitive and affective symptoms. Each item is rated on a four-point scale ranging from 0 to 3. A score of 4 or more indicates clinical depression. This score was found to correctly classify patients as being diagnosed with or without major depressive disorders (MDD) according to DSM-IV. The internal consistency is high $(\alpha=0.86)$. With regard to the convergent validity, the BDI-PC was positively associated with the diagnosis of MDD $(r=0.66, p<0.001)$ [35].

Functional Impairment

The Sickness Impact Profile short form 68 (SIP-68) was included in our study as it is a widely used measure of the impact of disease on an individual's physical and psychosocial functioning [36]. Patients are required to read through a list of conceivable difficulties and to identify which of these apply to them using a yes/no response format. Scores range between 0 and 68 , with a higher score indicating more functional impairment. The internal consistency is high; Cronbach's $\alpha=0.92$ [36, 37].

\section{Social Support}

The Van Sonderen Social Support Inventory (SSL) was used to assess social support [38]. Total scores of the SSL-I (number of social interactions) range from 34 to 136, a higher score meaning more social support. Subscales are emotional interactions, emotional support problems, esteem support, instrumental interactions, social companionship and informational support. The SSL has good reliability (Cronbach's $\alpha=0.93$ for SSL-I) and content validity [39].

\section{Self-Efficacy}

Self-efficacy, a sense of control over fatigue symptoms, was measured with a Self-Efficacy Fatigue Questionnaire. Seven items measured sense of control with respect to fatigue. Total scores range from 7 to 28 , a higher score meaning a patient experiences more control with respect to fatigue [17]. Cronbach's $\alpha$ reliability coefficients range from 0.70 to $0.77[18,40]$.

\section{Coping}

The subscales avoidance and problem-focused coping of the UCL (Utrechtse Coping List) were used to assess coping [41]. A high score on a subscale means that the individual uses that coping style often. The internal consistency is moderate to high ( $\alpha=0.66$ for avoidance, $\alpha=0.78$ for problem focused coping) [42].

\section{Anxiety}

In a previous study [7], the State-Trait Anxiety Inventory $[43,44]$ was not sensitive enough to measure specific anxiety in HPN patients. Therefore, a specific questionnaire was used to measure anxiety. Based on interviews in a 2003 study, six questions specific for anxiety in HPN patients were developed. These items were scored on a four-point scale ('not at all' to 'almost always'). Total scores ranged from 6 to 24, a higher score meaning a patient experiences more anxiety with respect to HPN complications or hospitalisations, future or even death.

\section{Acceptance}

Acceptance was measured with a subscale of the Illness Cognition Questionnaire. This questionnaire measures different patient cognitions about chronic illness and giving meaning in 
patients. The items are rated on a four-point scale (1, not at all, to 4 , completely), a higher score meaning better acceptance. The reliability (Cronbach's $\alpha=0.90$, test-retest reliability 0.76 ) and validity of acceptance were found to be high [45].

\section{Laboratory Measures}

Relevant laboratory measures were obtained from the medical records. We evaluated liver function (total bilirubin), renal function (creatinine), inflammation (albumin) and haemoglobin levels.

\section{Statistical Analysis}

Data analyses were performed using SPSS for Windows version 16.0. Variables were distributed normally, and therefore, parametric tests were performed. Descriptive statistics such as mean, standard deviation and range were used to describe the participants and to evaluate laboratory measurement outcomes. Paired-sample $t$ tests were performed to analyse differences between baseline and followup scores. Values of $p<0.05$ were considered statistically significant.

Associations between potential predictive variables at baseline and fatigue at follow-up were examined by calculating the Pearson's correlation coefficient. Pearson's correlation coefficient was also used to analyse relations between the predictive variables at baseline and to identify possible multicollinearity.

We performed a longitudinal linear regression analysis in which we entered variables which were possibly connected to fatigue at follow-up as independent variables and fatigue at follow-up as dependent variable (model 1). Subsequently, we performed a cross-sectional backward stepwise linear regression analysis with fatigue at baseline as dependent variable and potential predictive variables for fatigue from baseline as independent variables (model 2). This second model was added because we knew from literature that persistent fatigue could be predicted by the presence of fatigue at baseline alone [23]. Therefore, model 2 might give information on the relative importance of other important variables explaining fatigue. Predictive variables were removed from the model when they met the removal criterion of $p>0.05$.

\section{Results}

Patient Characteristics

The response rate at baseline was $71 \%$ (i.e. 75 out of 106 patients). No differences in gender, age, duration of HPN therapy or the indication for HPN were found between respondents and patients who refused to participate. At follow-up, 68 out of 75 patients were able to fill out the questionnaire again (Fig. 1). Eight patients discontinued HPN, but filled out the questionnaire at follow-up. The reason for discontinuing HPN was being able to eat sufficiently again due to adaptation of the remaining small intestinal mucosa in all patients. All follow-up analyses pertain to the 60 patients still on HPN. The eight patients who discontinued HPN were analysed separately.

Questionnaires that were completed by patients were checked, and in case of missing data, patients were contacted to complete the questionnaires. As no missing values occurred, all 60 cases were included in the analysis.

At baseline, patients' median age was 56 (range 19-81), $63 \%$ were women, $80 \%$ were married or cohabiting, and merely $20 \%$ was employed. Indications for HPN were short bowel syndrome, mostly related to inflammatory bowel disease or mesenteric thrombosis $(n=41,55 \%)$ and motility disorders $(n=34,45 \%$; Table 1$)$. Patients were on HPN for median 2 years (range 3 months to 30 years). Almost 75\% was able to use solid or liquid food to some extent.

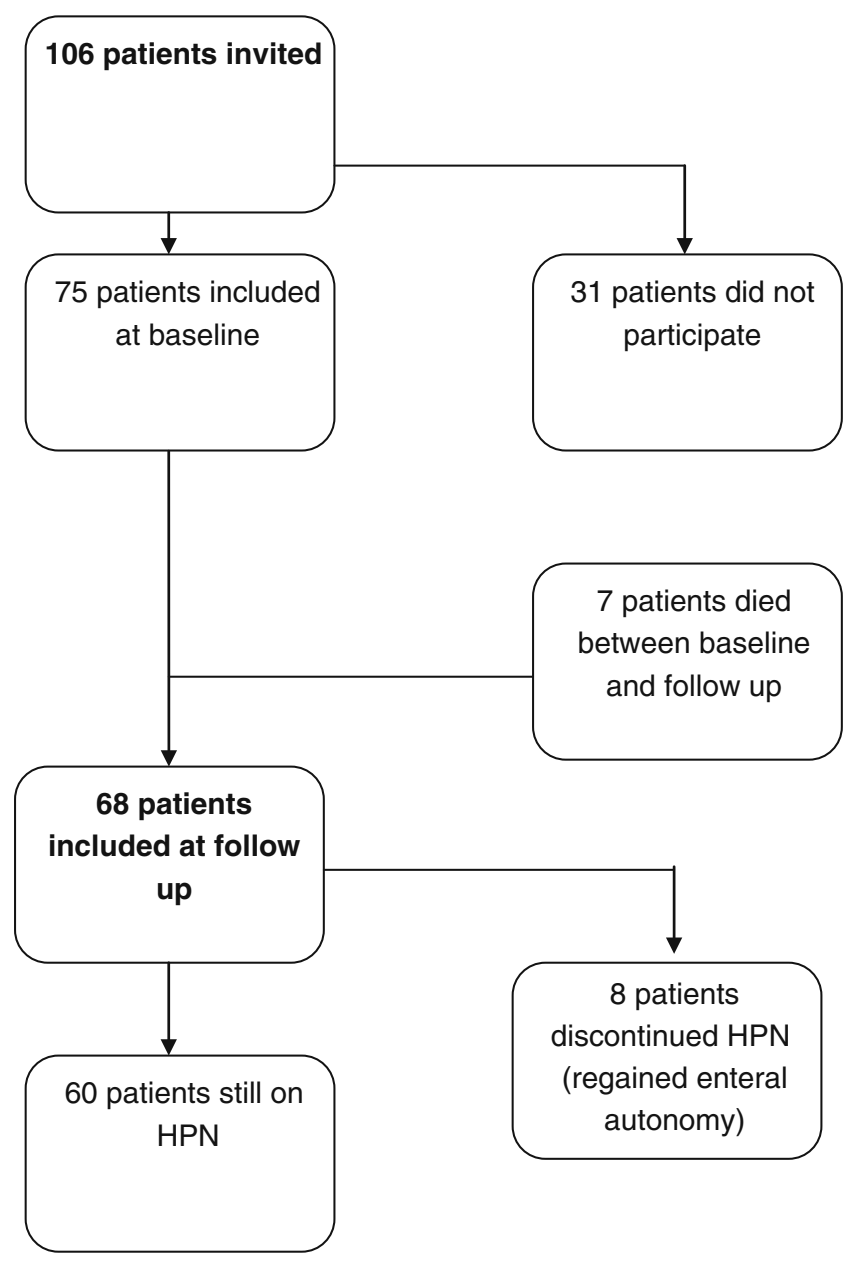

Fig. 1 Patient flowchart 
Table 1 Patient characteristics

\begin{tabular}{|c|c|c|c|}
\hline & $N=75$ \\
\hline \multicolumn{3}{|c|}{ Mean age (years) } & $53.1(\mathrm{SD} 12.8)$ \\
\hline \multicolumn{3}{|l|}{ Women, $N$} & $47(63 \%)$ \\
\hline \multicolumn{3}{|c|}{ Indication of HPN: short bowel syndrome (versus motility disorders) } & $41(55 \%)$ \\
\hline \multicolumn{3}{|l|}{ Years on HPN } & $5.0(\mathrm{SD} 6.2)$ \\
\hline & & $\mathrm{T} 1$ & $\mathrm{~T} 2$ \\
\hline \multirow[t]{2}{*}{ Haemoglobin } & Mean (SD) & 7.4 & 7.4 \\
\hline & Percentiles $25-75$ & $7.1-8.0$ & $7.0-7.9$ \\
\hline \multirow[t]{2}{*}{ Albumin } & Mean (SD) & $35.8(4.9)$ & $36.9(4.9)$ \\
\hline & Percentiles $25-75$ & $36.5-41.0$ & $34.0-40.0$ \\
\hline \multirow[t]{2}{*}{ Total bilirubin } & Mean (SD) & $10.5(10.9)$ & $8.6(6.7)$ \\
\hline & Percentiles $25-75$ & $5.0-12.0$ & $4.0-12.0$ \\
\hline \multirow[t]{2}{*}{ Creatinine } & Mean (SD) & 77.8 & 85.2 \\
\hline & Percentiles $25-75$ & $58.8-87.0$ & $62.0-91.5$ \\
\hline
\end{tabular}

Serum haemoglobin, creatinine, albumin and bilirubin were in accordance with the reference ranges (Table 1) and therefore did not indicate the occurrence of fatigue in the patient population. These laboratory measures were not included in our analysis because they did not correlate significantly with fatigue.

\section{Prevalence and Course of Fatigue}

The baseline fatigue score was $37.9 \pm 13.6$ (mean, SD), and $62 \%$ of all patients scored 35 or higher. At follow-up, the mean fatigue score was $38.8 \pm 13.2$ (difference $0.9, p=0.45$ ); $63 \%$ of the patients scored 35 or higher. The correlation between baseline and follow-up CIS fatigue scores was $0.75(p<0.001)$. Eighty-nine per cent of the patients who were identified as severely fatigued at baseline were severely fatigued at follow-up as well (Table 2).

Patients who discontinued HPN at follow-up $(n=8)$ had a mean age of $44 \pm 12$ (median 47); five of them were women, five were married or cohabiting, and five of them were employed. They showed a mean fatigue score of $43.1 \pm 10.0$ at follow-up. This did not differ from their baseline fatigue score (mean $43.8 \pm 10.3, p=<0.001$ ). Five of these were identified as severely fatigued at both baseline and follow-up.

Predictors of Fatigue

The correlations between the predictive variables and fatigue at follow-up are presented in Table 3. We found multicollinearity between depression and acceptance $(r=-0.651)$ and between depression and anxiety $(r=0.628)$. Based on these results, acceptance and anxiety were excluded, and avoidance, social companionship, functional impairment, self-efficacy and depression were included in the regression analysis.

The longitudinal analysis with fatigue at follow-up as dependent variable and fatigue, depression, self-efficacy, avoidance, functional impairment and social companionship at baseline as independent variables showed that $60 \%$ of the variance in fatigue was predicted by fatigue and avoidance. Fatigue was responsible for $57 \%$, and avoidance was responsible for $3 \%$ of the variance (Table 4 , model 1 ).

Cross-sectionally, the analysis with baseline fatigue as dependent variable and depression, self-efficacy, avoidance, functional impairment and social companionship at baseline

Table 2 Course of fatigue

\begin{tabular}{lccc}
\hline $\mathrm{T} 1$ & $\mathrm{~T} 2$ & & \\
\cline { 2 - 4 } & Severe fatigue at follow-up & Heightened fatigue at follow-up & No fatigue at follow-up \\
\hline Severe fatigue at baseline $(n=37)$ & $33(89 \%)$ & $2(5.5 \%)$ & $2(5.5 \%)$ \\
Heightened fatigue at baseline $(n=8)$ & $3(37.5)$ & $2(25)$ & $3(37.5)$ \\
No fatigue at baseline $(n=15)$ & $2(13.3)$ & $5(33.3)$ & $8(53.3)$
\end{tabular}

The course of fatigue: numbers and percentages of patients that were classified as severely, heightened or not fatigued at follow-up on the basis of their classification as severely, heightened or not fatigued at baseline 
Table 3 Pearson correlations between possible continuous predictors at baseline and fatigue at follow-up

\begin{tabular}{lc}
\hline & Fatigue \\
\hline Coping & \\
Active problem solving & -0.098 \\
Avoidance & $0.330^{* *}$ \\
Health cognitions & \\
Acceptance & $-0.369^{* *}$ \\
SSL-I (amount of social interactions) & \\
Total & -0.157 \\
Emotional interactions & -0.214 \\
Emotional support problems & -0.022 \\
Esteem support & -0.185 \\
Instrumental interactions & 0.048 \\
Social companionship & $-0.257^{*}$ \\
Informational support & -0.166 \\
SSL-N (negative interactions) & 0.230 \\
SIP-Total & $0.511^{* *}$ \\
Self-efficacy fatigue & $-0.443^{* *}$ \\
Anxiety & $0.369^{* *}$ \\
BDI-PC & $0.444^{* *}$ \\
CIS-Fatigue & $0.745^{* *}$ \\
Laboratory measures & \\
Haemoglobin & 0.086 \\
Albumin & -0.139 \\
Total bilirubin & -0.242 \\
Creatinine & -0.036 \\
\hline & \\
\hline & \\
&
\end{tabular}

$* p=<0.05 ; * * p=<0.01$

as independent variables showed that $46 \%$ of fatigue was explained by functional impairment, self-efficacy and depression. Functional impairment was responsible for $31 \%$ of the variance, self-efficacy for $11 \%$, and depression was responsible for $4 \%$ (Table 4 , model 2 ).

\section{Discussion}

We found that severe fatigue is a persistent problem in the daily life of HPN patients. This finding has also been reported in other patient categories, such as (disease-free) breast cancer patients [23], chronic peritoneal dialysis patients [13] and patients suffering from rheumatoid arthritis [24]. For HPN patients, no predictors of fatigue were available from the literature. Our first longitudinal analysis showed that fatigue is the most important predictor for persistent fatigue. This result has also been found by Servaes et al. [23] in disease-free breast cancer patients. Avoidance was the second predictor of fatigue in HPN patients. From literature in CFS patients, it is known that patients avoid all kinds of activities because of the fear that activity enhances symptoms [46]. Because the body gets unused to activity, symptoms will emerge at increasingly lower levels of activity. In this way, a self-fulfilling prophecy is established. Motivating patients and decreasing the fear of activity therefore is important to decrease levels of fatigue. Our second cross-sectional analysis showed that functional impairment, self-efficacy and depression explain a considerable part of fatigue at baseline.

Whilst fatigue is a frequent symptom in HPN patients, it has received no attention in research. As HPN patients may suffer from anaemia, problems with fluid intake/diarrhoea, renal disease or liver disease, it is reasonable to assume that fatigue is related to somatic problems. However, our results show no correlations between relevant laboratory measures and fatigue. This is in accordance with several studies in patients on haemodialysis and in patients with primary biliary cirrhosis where no association was found between anaemia, albumin, creatinine and bilirubin levels and fatigue [12, 28-31].

As in our study, studies in patients suffering from rheumatoid arthritis show that the relationships between psychosocial variables and fatigue are often much stronger than 'objective' measures of disease severity or inflammatory markers, like laboratory values, swollen joints or deformities [47-49]. Riemsma et al. [50] showed that laboratory measurements like haemoglobin concentration and erythrocyte sedimentation rate are not significantly related to fatigue, whilst psychosocial aspects like selfefficacy and problematic social support are the most important variables in explaining fatigue.

With regard to the results for functional impairment, it can be concluded that HPN patients experiencing more functional impairment have higher levels of fatigue. Regarding selfefficacy, a lower sense of control with respect to fatigue complaints is associated with an increase in experienced fatigue. Both these findings are consistent with results of studies in chronic fatigue syndrome patients, multiple sclerosis patients and patients with rheumatoid arthritis $[17,50]$. In these patient populations, a low self-efficacy was found to have a direct negative causal effect on fatigue severity. It is known that self-efficacy can be enhanced by self-management courses, and it may thus be possible to improve fatigue [50]. Self-efficacy is also an important aspect of cognitive behaviour therapy in CFS patients. Prins et al. [40] found that patients with a greater sense of control at baseline had a larger decrease in fatigue severity after cognitive behaviour therapy (CBT) than patients with lower sense of control.

For CFS patients, CBT has been proven to be successful in reducing fatigue complaints [40, 51-53]. Besides reducing fatigue severity, $\mathrm{CBT}$ also had a positive effect on functional impairment [40]. A systematic review of Neill et al. [54] showed the effectiveness of non-pharmacological interventions for fatigue in chronic diseases. Exercise 
Table 4 Linear multiple regression of complete model and final model

\begin{tabular}{|c|c|c|c|c|c|}
\hline & & $B$ & SE $B$ & $\beta$ & $p$ value \\
\hline \multirow[t]{12}{*}{ Model 1} & Complete model & & & & \\
\hline & Constant & 13.926 & 11.333 & & 0.224 \\
\hline & Fatigue baseline & 0.653 & 0.106 & 0.659 & 0.000 \\
\hline & Social companionship & 0.262 & 0.371 & 0.65 & 0.483 \\
\hline & Avoidance & 0.537 & 0.309 & 0.149 & 0.087 \\
\hline & Functional impairment & 0.110 & 0.502 & 0.088 & 0.400 \\
\hline & BDI & -0.245 & 0.502 & -0.053 & 0.627 \\
\hline & Self-efficacy & -0.704 & 0.394 & -0.167 & 0.079 \\
\hline & Final model & & & & \\
\hline & Constant & 1.777 & 5.231 & & 0.735 \\
\hline & Fatigue baseline & 0.714 & 0.082 & 0.720 & 0.000 \\
\hline & Avoidance & 0.597 & 0.298 & 0.165 & 0.049 \\
\hline \multirow[t]{12}{*}{ Model 2} & Complete model & & & & \\
\hline & Constant & 50.408 & 10.833 & & 0.000 \\
\hline & Social companionship & -0.158 & 0.425 & -0.038 & 0.711 \\
\hline & Avoidance & 0.040 & 0.355 & 0.011 & 0.911 \\
\hline & Functional impairment & 0.463 & 0.138 & 0.364 & 0.001 \\
\hline & BDI & 1.041 & 0.568 & 0.218 & 0.071 \\
\hline & Self-efficacy & -1.062 & 0.402 & -0.269 & 0.010 \\
\hline & Final model & & & & \\
\hline & Constant & 49.472 & 7.742 & & 0.000 \\
\hline & Functional impairment & 0.465 & 0.136 & 0.366 & 0.001 \\
\hline & BDI & 1.102 & 0.535 & 0.230 & 0.043 \\
\hline & Self-efficacy & -1.100 & 0.385 & -0.279 & 0.006 \\
\hline
\end{tabular}

appears to be an effective, appropriate and feasible nonpharmacological intervention for reducing fatigue in people with multiple sclerosis (MS), rheumatoid arthritis (RA), and systemic lupus erythematosus (SLE). This is consistent with recommendations for patients with cancer-related fatigue and chronic fatigue syndrome. In addition, a range of behavioural interventions, like energy conservation, may be helpful in reducing fatigue in MS, RA and SLE [55-57]. Educational interventions also produced statistically significant reductions in fatigue.

The finding that depression partly explains fatigue is also confirmed by other studies on fatigue. Leserman et al. [58] showed that depression directly results in fatigue. Lui [22] found that depression was the most important predictor of fatigue in haemodialysis patients. Although this remains to be proven in future research, in our opinion, the adequate identification and treatment for depression might also prove to be an effective strategy for decreasing levels of fatigue [22, 59]. In HPN patients, a study by Smith et al. [60] showed that by means of interactive education, depressive reactions can be prevented and the patients' capacity to solve problems is promoted. This intervention also led to a higher health-related quality of life.

Surprisingly, fatigue also was a main problem in patients who discontinued HPN. Their fatigue scores were higher than those in patients still on HPN. This can possibly be explained by having less energy because of their nutritional status. To maintain their body weight, these patients have to eat often during the day.

Importantly, we included about $70 \%$ of all Dutch HPN patients who were treated according to largely similar protocols. The $30 \%$ not included in this study did not differ from our sample in gender, age, duration or indication for HPN. Therefore, the sample seems representative of the whole population of HPN patients in the Netherlands. Unfortunately, reasons for not participating are unknown.

We used validated questionnaires and a strength of our present study is that there were no missing data. With the exception of the patients who died, there was no loss to follow-up in 2007.

A weakness of this study, however, is that although we included about $70 \%$ of the Dutch HPN population, the sample size as a whole remains relatively small. Due to this problem, we could only include the total SIP-68 score in our analysis and not its different subscales. Based on these notions, an additional longitudinal, and ideally a multicentre international study, is recommended. Several factors, including variables of disease severity, subscales of the SIP68, sleep disturbance, and general and HPN-related characteristics could be included in this study. 
The importance of identifying modifiable factors to predict fatigue is that these can help in the prevention and treatment of this problem.

Acknowledgement We would like to thank Reinier Akkermans for his input concerning the statistical analysis. No funding was received for this investigation. All authors disclose any financial and personal relationship with other people or organization that could inappropriately influence (bias) their work.

Open Access This article is distributed under the terms of the Creative Commons Attribution Noncommercial License which permits any noncommercial use, distribution, and reproduction in any medium, provided the original author(s) and source are credited.

\section{References}

1. Winkler MF. Quality of life in adult home parenteral nutrition patients. JPEN J Parenter Enteral Nutr. 2005;29(3):162-70.

2. Siepler J. Principles and strategies for monitoring home parenteral nutrition. Nutr Clin Pract. 2007;22(3):340-50.

3. Howard L, Ashley C. Management of complications in patients receiving home parenteral nutrition. Gastroenterology. 2003;124 (6):1651-61.

4. Shirotani N, Iino T, Numata K, Kameoka S. Complications of central venous catheters in patients on home parenteral nutrition: an analysis of 68 patients over 16 years. Surg Today. 2006;36(5):420-4.

5. Bozzetti F, Mariani L, Bertinet DB, Chiavenna G, Crose N, De $\mathrm{CM}$, et al. Central venous catheter complications in 447 patients on home parenteral nutrition: an analysis of over 100.000 catheter days. Clin Nutr. 2002;21(6):475-85.

6. Carlson GL, Maguire G, Williams N, Bradley A, Shaffer JL, Irving $\mathrm{MH}$. Quality of life on home parenteral nutrition: a single centre study of 37 patients. Clin Nutr. 1995;14(4):219-28.

7. Huisman-de WG, Naber T, Schoonhoven L, Persoon A, Sauerwein $\mathrm{H}$, van Achterberg T. Problems experienced by patients receiving parenteral nutrition at home: results of an open interview study. JPEN J Parenter Enteral Nutr. 2006;30(3):215-21.

8. Huisman-de WG, Schoonhoven L, Jansen J, Wanten G, van Achterberg T. The impact of home parenteral nutrition on daily life - a review. Clin Nutr. 2007;26(3):275-88.

9. Persoon A, Huisman-de WG, Naber TA, Schoonhoven L, Tas T, Sauerwein $\mathrm{H}$, et al. Impact of long-term HPN on daily life in adults. Clin Nutr. 2005;24(2):304-13.

10. Smith CE, Curtas S, Werkowitch M, Kleinbeck SV, Howard L. Home parenteral nutrition: does affiliation with a national support and educational organization improve patient outcomes? JPEN J Parenter Enteral Nutr. 2002;26(3):159-63.

11. de Bruin AF. The measurement of sickness impact: the construction of the SIP-68. Thesis, Rijksuniversiteit Limburg; 1996.

12. McCann K, Boore JR. Fatigue in persons with renal failure who require maintenance haemodialysis. J Adv Nurs. 2000;32 (5):1132-42.

13. Ossareh S, Roozbeh J, Krishnan M, Liakopoulos V, Bargman JM, Oreopoulos DG. Fatigue in chronic peritoneal dialysis patients. Int Urol Nephrol. 2003;35(4):535-41.

14. Servaes P, van der Werf S, Prins J, Verhagen S, Bleijenberg G. Fatigue in disease-free cancer patients compared with fatigue in patients with chronic fatigue syndrome. Support Care Cancer. 2001;9(1):11-7.

15. Skerrett TN, Moss-Morris R. Fatigue and social impairment in multiple sclerosis: the role of patients' cognitive and behavioral responses to their symptoms. J Psychosom Res. 2006;61(5):587-93.
16. Vercoulen JH, Hommes OR, Swanink CM, Jongen PJ, Fennis JF, Galama JM, et al. The measurement of fatigue in patients with multiple sclerosis. A multidimensional comparison with patients with chronic fatigue syndrome and healthy subjects. Arch Neurol. 1996;53(7):642-9.

17. Vercoulen JH, Swanink CM, Galama JM, Fennis JF, Jongen PJ, Hommes OR, et al. The persistence of fatigue in chronic fatigue syndrome and multiple sclerosis: development of a model. J Psychosom Res. 1998;45(6):507-17.

18. Servaes P, Verhagen S, Bleijenberg G. Determinants of chronic fatigue in disease-free breast cancer patients: a cross-sectional study. Ann Oncol. 2002;13(4):589-98.

19. van der Werf SP, de VB, Alberts M, van der Meer JW, Bleijenberg G. Natural course and predicting self-reported improvement in patients with chronic fatigue syndrome with a relatively short illness duration. J Psychosom Res. 2002;53(3):749-53.

20. Darbishire L, Seed P, Ridsdale L. Predictors of outcome following treatment for chronic fatigue. Br J Psychiatry. 2005;186:350-1.

21. Vercoulen JH, Swanink CM, Fennis JF, Galama JM, van der Meer JW, Bleijenberg G. Dimensional assessment of chronic fatigue syndrome. J Psychosom Res. 1994;38(5):383-92.

22. Liu HE. Fatigue and associated factors in hemodialysis patients in Taiwan. Res Nurs Health. 2006;29(1):40-50.

23. Servaes P, Gielissen MF, Verhagen S, Bleijenberg G. The course of severe fatigue in disease-free breast cancer patients: a longitudinal study. Psychooncology. 2007;16(9):787-95.

24. Repping-Wuts $H$, Uitterhoeve $R$, van Riel $P$, van Achterberg $T$. Fatigue as experienced by patients with rheumatoid arthritis (RA): a qualitative study. Int J Nurs Stud. 2008;45(7):995-1002.

25. Simren M, Svedlund J, Posserud I, Bjornsson ES, Abrahamsson $\mathrm{H}$. Predictors of subjective fatigue in chronic gastrointestinal disease. Aliment Pharmacol Ther. 2008;28(5):638-47.

26. Srivastava RH. Fatigue in the renal patient. ANNA J. 1986;13 (5):246-9.

27. Piper BF, Lindsey AM, Dodd MJ. Fatigue mechanisms in cancer patients: developing nursing theory. Oncol Nurs Forum. 1987;14 (6):17-23.

28. Cauch-Dudek K, Abbey S, Stewart DE, Heathcote EJ. Fatigue in primary biliary cirrhosis. Gut. 1998;43(5):705-10.

29. Bjornsson E, Simren M, Olsson R, Chapman RW. Fatigue is not a specific symptom in patients with primary biliary cirrhosis. Eur $\mathrm{J}$ Gastroenterol Hepatol. 2005;17(3):351-7.

30. Brunier GM, Graydon J. The influence of physical activity on fatigue in patients with ESRD on hemodialysis. ANNA J. 1993;20 (4):457-61.

31. Sklar AH, Riesenberg LA, Silber AK, Ahmed W, Ali A. Postdialysis fatigue. Am J Kidney Dis. 1996;28(5):732-6.

32. Vercoulen JH, Alberts M, Bleijenberg G. De checklist individual strength (CIS). Gedragstherapie. 1994;38:131-6.

33. Vercoulen JH, Alberts M, Bleijenberg G. De checklist individual strength (CIS). Gedragstherapie. 1999;32(2):131-6.

34. Beck AT, Ward CH, Mendelson M, Mock J, Erbaugh J. An inventory for measuring depression. Arch Gen Psychiatry. 1961;4:561-71.

35. BECK AT, Guth D, Steer RA, Ball R. Screening for major depression disorders in medical inpatients with the beck depression inventory for primary care. Behav Res Ther. 1997;35(8):785-91.

36. Post MW, de Bruin A, de Witte L, Schrijvers A. The SIP68: a measure of health-related functional status in rehabilitation medicine. Arch Phys Med Rehabil. 1996;77(5):440-5.

37. Post MW, Gerritsen J, Diederikst JP, DeWittet LP. Measuring health status of people who are wheelchair-dependent: validity of the sickness impact profile 68 and the Nottingham health profile. Disabil Rehabil. 2001;23(6):245-53.

38. Van Sonderen E. Sociale steun lijst-Interacties (SSL-i) en Sociale steun lijst-Discrepanties (SSL-d). Groningen: Noordelijk Centrum voor Gezondheidsvraagstukken; 1993. 
39. Van Sonderen E, Ormel J. Het meten van aspecten van sociale steun en hun relatie met welbevinden. Gedrag Gezondheid. 1997;25:190-200 (magazine article).

40. Prins JB, Bleijenberg G, Bazelmans E, Elving LD, de Boo TM, Severens JL, et al. Cognitive behaviour therapy for chronic fatigue syndrome: a multicentre randomised controlled trial. Lancet. 2001;357(9259):841-7.

41. Schreurs P, Van de Wilige G, Brosschot JF, Tellegen B, Graus GMH. De Utrechtse Coping Lijst: UCL-herziene handleiding. Leiden: Swets Test Publishers; 1993.

42. Schaufeli W, van Dierendonck D. De betrouwbaarheid en validiteit van de Utrechtse Coping Lijst: een longitudinaal onderzoek bij schoolverlaters. Gedrag gezond. 1992;20(1):38-45 (magazine article).

43. Spielberger CD. Assessment of state and trait anxiety: conclusions and methodological issues. South Psychol. 1985;2:6-16.

44. Van der Ploeg HM, Defares PB, Spielberger CD. Handleiding bij de Zelf-Beoordelings Vragenlijst; 1980.

45. Evers AW, Kraaimaat FW, Van LW, Jongen PJ, Jacobs JW, Bijlsma JW. Beyond unfavorable thinking: the illness cognition questionnaire for chronic diseases. J Consult Clin Psychol. 2001;69(6):1026-36.

46. Bazelmans E, Prins JB, Bleijenberg G. Cognitive behaviour therapy for relatively active and for passive chronic fatigue syndrome patients. Cogn behav pract. 2006;13:157-66.

47. Belza BL, Henke CJ, Yelin EH, Epstein WV, Gilliss CL. Correlates of fatigue in older adults with rheumatoid arthritis. Nurs Res. 1993;42(2):93-9.

48. Lorish CD, Abraham N, Austin J, Bradley LA, Alarcon GS. Disease and psychosocial factors related to physical functioning in rheumatoid arthritis. J Rheumatol. 1991;18(8):1150-7.

49. Wolfe F, Hawley DJ, Wilson K. The prevalence and meaning of fatigue in rheumatic disease. J Rheumatol. 1996;23(8):1407-17.

50. Riemsma RP, Rasker JJ, Taal E, Griep EN, Wouters JM, Wiegman O. Fatigue in rheumatoid arthritis: the role of self-efficacy and problematic social support. Br J Rheumatol. 1998;37(10):1042-6.
51. Bazelmans E, Prins JB, Lulofs R, van der Meer JW, Bleijenberg G. Cognitive behaviour group therapy for chronic fatigue syndrome: a non-randomised waiting list controlled study. Psychother Psychosom. 2005;74(4):218-24.

52. Deale A, Chalder T, Marks I, Wessely S. Cognitive behavior therapy for chronic fatigue syndrome: a randomized controlled trial. Am J Psychiatry. 1997;154(3):408-14.

53. Stulemeijer M, de Jong LW, Fiselier TJ, Hoogveld SW, Bleijenberg G. Cognitive behaviour therapy for adolescents with chronic fatigue syndrome: randomised controlled trial. BMJ. 2005;330(7481):14.

54. Neill J, Belan I, Ried K. Effectiveness of non-pharmacological interventions for fatigue in adults with multiple sclerosis, rheumatoid arthritis, or systemic lupus erythematosus: a systematic review. J Adv Nurs. 2006;56(6):617-35.

55. Mathiowetz V, Matuska KM, Murphy ME. Efficacy of an energy conservation course for persons with multiple sclerosis. Arch Phys Med Rehabil. 2001;82(4):449-56.

56. Mathiowetz VG, Finlayson ML, Matuska KM, Chen HY, Luo P. Randomized controlled trial of an energy conservation course for persons with multiple sclerosis. Mult Scler. 2005;11(5):592-601.

57. Vanage SM, Gilbertson KK, Mathiowetz V. Effects of an energy conservation course on fatigue impact for persons with progressive multiple sclerosis. Am J Occup Ther. 2003;57(3):315-23.

58. Leserman J, Barroso J, Pence BW, Salahuddin N, Harmon JL. Trauma, stressful life events and depression predict HIV-related fatigue. AIDS Care. 2008;20(10):1258-65.

59. Wuerth D, Finkelstein SH, Ciarcia J, Peterson R, Kliger AS, Finkelstein FO. Identification and treatment of depression in a cohort of patients maintained on chronic peritoneal dialysis. Am J Kidney Dis. 2001;37(5):1011-7.

60. Smith CE, Curtas S, Kleinbeck SV, Werkowitch M, Mosier M, Seidner DL, et al. Clinical trial of interactive and videotaped educational interventions reduce infection, reactive depression, and rehospitalizations for sepsis in patients on home parenteral nutrition. JPEN J Parenter Enteral Nutr. 2003;27(2):137-45. 